\title{
Does a Wii-based exercise program enhance balance control of independently functioning older adults? A systematic review
}

This article was published in the following Dove Press journal:

Clinical Interventions in Aging

23 October 2014

Number of times this article has been viewed

\section{Yocheved Laufer \\ Gali Dar \\ Einat Kodesh}

Physical Therapy Department, Faculty of Social Welfare and Health Sciences, University of Haifa, Haifa, Israel
Correspondence: Yocheved Laufer Physical Therapy Department, Faculty of Social Welfare and Health Sciences, University of Haifa, Haifa, Israel 31905 Email yocheved@research.haifa.ac.il
Background: Exercise programs that challenge an individual's balance have been shown to reduce the risk of falls among older adults. Virtual reality computer-based technology that provides the user with opportunities to interact with virtual objects is used extensively for entertainment. There is a growing interest in the potential of virtual reality-based interventions for balance training in older adults. This work comprises a systematic review of the literature to determine the effects of intervention programs utilizing the Nintendo Wii console on balance control and functional performance in independently functioning older adults.

Methods: Studies were obtained by searching the following databases: PubMed, CINAHL, PEDro, EMBASE, SPORTdiscus, and Google Scholar, followed by a hand search of bibliographic references of the included studies. Included were randomized controlled trials written in English in which Nintendo Wii Fit was used to enhance standing balance performance in older adults and compared with an alternative exercise treatment, placebo, or no treatment.

Results: Seven relevant studies were retrieved. The four studies examining the effect of Wiibased exercise compared with no exercise reported positive effects on at least one outcome measure related to balance performance in older adults. Studies comparing Wii-based training with alternative exercise programs generally indicated that the balance improvements achieved by Wii-based training are comparable with those achieved by other exercise programs.

Conclusion: The review indicates that Wii-based exercise programs may serve as an alternative to more conventional forms of exercise aimed at improving balance control. However, due to the great variability between studies in terms of the intervention protocols and outcome measures, as well as methodological limitations, definitive recommendations as to optimal treatment protocols and the potential of such an intervention as a safe and effective home-based treatment cannot be made at this point.

Keywords: virtual reality, exergame, balance, exercise, falls

\section{Introduction}

Approximately one third of individuals aged 65 years or older experience at least one fall a year, ${ }^{1,2}$ with over $40 \%$ of falls resulting in significant physical injury or death. ${ }^{3}$ Fall-related injuries, as well as fear of falling, contribute to reduced mobility, which curtails an individual's participation in daily activities, leading ultimately to a decline in quality of life. ${ }^{3,4}$ With increased life expectancy in developed countries, fall prevention has become an urgent global health challenge. ${ }^{5}$

Causes of falls are multifaceted and their prevention requires a comprehensive, multidimensional treatment strategy. ${ }^{2,6-8}$ It is well documented that some of the risk factors for falls related to the neuromuscular system, such as impaired balance and gait as well as reduced muscle strength, can be modified by appropriate exercise 
programs..$^{9-11}$ A systematic review aimed at establishing whether particular components of an exercise program are associated with a greater decrease in falls determined that larger relative effects on fall prevention are seen in programs that include exercises focusing on balance control. ${ }^{12}$ Thus, intervention programs incorporating exercises that challenge balance, such as Tai Chi exercises, have been shown to reduce the risk of falls among older adults. ${ }^{13,14}$ The intensity of the balance-focused exercise program and the need to adhere to it throughout one's lifetime are crucial for successful fall prevention. ${ }^{12}$ Therefore, intervention programs must be designed to encourage exercise compliance by stimulating motivation and being easily accessible, while at the same time having no adverse effects.

Virtual reality (VR) computer-based technology provides the user with opportunities to interact with virtual objects and events that simulate the real world. ${ }^{15,16}$ By offering the user the opportunity to interact with a variety of engaging activities, some of which may be too risky when practiced in the real world, VR technology can encourage repetitive taskspecific behavior graded to the competence level of the user, while providing the feedback necessary for effective motor learning. ${ }^{17,18}$ Thus, VR-based exercise can provide experiential, active learning opportunities that are fun, motivating, and challenging whilst being safe and ecologically valid. ${ }^{17}$ Due to its potential as a means to enhance motor and cognitive learning, VR technology is emerging as a rehabilitation tool for individuals with a variety of physical disabilities, including stroke, ${ }^{19}$ Parkinson's disease, ${ }^{20}$ and cerebral palsy. ${ }^{21}$

The use of VR technology has rapidly expanded in the last decade, with the introduction of off-the-shelf commercial consoles and games. Although these systems were developed for entertainment purposes, they have evolved as a means to encourage fitness exercise (termed exergames) in the general population. ${ }^{22,23}$ As commercial systems are much less expensive than custom-developed rehabilitation tools, off-the-shelf systems are also gaining popularity as treatment modalities for motor and cognitive rehabilitation of subjects with a variety of orthopedic and neurological impairments. ${ }^{24-26} \mathrm{Of}$ the four best known commercial systems (Nintendo Wii, Dance Dance Revolution, Playstation EyeToy, and Microsoft Kinect), ${ }^{27,28}$ Nintendo Wii is the most popular system applied for rehabilitation purposes. Thus, a recent systematic review of commercial systems used for rehabilitation of the upper limb following a stroke identified ten studies that utilized the Nintendo Wii and only two that used the PlayStation Eye Toy. ${ }^{29}$ In a similar systematic review regarding the use of VR in Parkinson's disease, all six studies identified utilized the Nintendo Wii system. ${ }^{30} \mathrm{~A}$ recent audit by the National Stroke Foundation of Australia found that 84 of 111 (76\%) metropolitan stroke rehabilitation hospitals purchased a Nintendo Wii console. ${ }^{31}$ Further, in a preliminary literature review, we did not identify any randomized controlled studies on the effects of VR-based interventions on balance control in older adults with commercial systems other than the Nintendo Wii.

The popularity of this system is probably due to the variety of video games enabled through both the Wii Remote (Wiimote) and the Wii Balance Board (Nintendo of America Inc., Redmond, WA, USA) peripheral devices. The Wiimote incorporates three-dimensional accelerometer technology that tracks arm movements and can be used, for example, to encourage players to mimic movements performed in real-life sports, such as swinging a tennis racquet. The Wii Balance Board is a platform device capable of monitoring changes in the individual's center of pressure. It is employed in conjunction with Wii Fit software and uses an avatar to provide feedback regarding changes in one's center of pressure throughout a variety of interactive games. Both peripheral devices can be used in games that challenge an individual's balance capabilities, while providing appropriate visual and auditory feedback regarding balance performance.

Since the Wii gaming console was introduced to the market in 2006, there has been a growing interest in its potential for balance training in older adults. Whereas preliminary studies involved only single-case design $\mathrm{s}^{32,33}$ or single-group designs (with no control group), ${ }^{34,35}$ a number of studies of higher methodological quality have been published in the last few years. The primary objective of the present study was to systematically review randomized controlled trials that examined the effects of intervention programs utilizing the Nintendo Wii console on balance control in independently functioning older adults. The success of such interventions was reviewed in comparison with alternative exercise programs, as well as with no exercise intervention. The present review was written in accordance with the guidelines recommended by the PRISMA (Preferred Reporting Items for Systematic Reviews and Meta-Analysis) statement. ${ }^{36}$

\section{Methods}

\section{Search strategy}

An online search of the PubMed (since 1966), CINAHL (since 1982), PEDro, EMBASE (since 1974), SPORTdiscus (since 1930), and Google Scholar databases was performed independently by two of the authors (YL, EK). The last full search was conducted in June 2014. The electronic search 
was completed by a hand search of bibliographic references of the included studies.

The search terms used were: "virtual reality", "video game", "exergame", and "Wii Fit", crossed with "balance", "postural control", or "falls". The search was restricted to the English language. The search was initially conducted by two of the authors independently (YL, EK) and finalized by the authors in collaboration. Duplicate publications were removed after all databases and reference lists were searched. The titles and abstracts of all identified articles were reviewed, with the full article reviewed whenever deemed necessary to finalize a decision about inclusion.

\section{Study inclusion and exclusion criteria}

The authors screened all selected citations independently. Study inclusion criteria were:

- Randomized controlled trials appearing in refereed journals.

- Trials in which a VR exergame based on Nintendo Wii was used to enhance standing balance performance in comparison with an alternative exercise treatment that did not involve VR or interactive computer gaming, or in comparison with a placebo treatment, or with no treatment at all. In cases where a conventional exercise program was added to the Wii-based intervention, the article was included only if the same conventional program was offered to the control group.

- Participants were adults aged 55 years or older living in the community or independently in retirement centers.

- Participants were referred to the VR intervention primarily to improve standing/walking balance control.

- Participants were without cognitive impairment and were able to ambulate independently with/out assistive devices, with/out a history of falls.

- A report of at least one outcome measure assessing standing/walking balance capabilities, fall incidence, or fall efficacy.

Exclusion criteria were:

- Studies designed to address populations with specific neurological (ie, stroke, Parkinson's disease, and multiple sclerosis), metabolic (ie, diabetes), or musculoskeletal (ie, rheumatoid arthritis) deficits that might impair balance control.

- Studies with a PEDro score of $\leq 4$.

- Studies with less than six participants in each intervention group.

- Studies in which no inferential statistics were reported.
- Studies reported in conference proceedings, posters, theses, or dissertations.

\section{Data extraction}

A data extraction form was developed by the reviewers that included the following details: number of male and female subjects in each treatment group; subjects' mean age (standard deviation [SD]) per group; type of Wii peripherals and Wii games used; type of control group intervention; subjects' residence, location of intervention; provision of supervision during intervention; number of treatments per week; number of treatment weeks; duration of each treatment; statistical analyses employed; outcome measures assessed; and statistically significant changes per outcome measure. Each author extracted the data independently, and differences between the reviewers in regard to the data summary were discussed and resolved in a face-to-face meeting.

\section{Quality assessment}

The methodological quality of the included studies was assessed in accordance with the PEDro classification scale, providing a score between 0 to $10 .^{37}$ The PEDro ratings, which are provided by the Centre for Evidence-Based Physiotherapy at the George Institute for Global Health (http:// ptwww.cchs.usyd.edu.au/), were used whenever available. Studies for which a PEDro score was not published were scored independently by the authors, with discrepancies discussed in a face-to-face meeting and resolved by agreement. Due to the nature of the studies, blindness of the subjects or the individuals providing the treatment was not possible; hence, the maximum possible score was 8 . Studies were rated between excellent and poor on the basis of the PEDro score as follows: 8-7 (excellent), 6 (good), and 4-5 (fair).

\section{Results Study selection}

Initial screening resulted in a total of 351 papers, of which 39 were considered relevant on the basis of their title and abstract. Full text review of these studies indicated that eight randomized controlled trials met all the inclusion criteria for review. Two of these articles were considered as a single study, since consultation with their primary author determined that they reported different outcome measures obtained from the same data set. ${ }^{38,39}$ Thus, the final review included seven randomized controlled trials. The selection process for the studies included in this systematic review is presented in Figure 1. Characteristics of the final seven studies retrieved are summarized in Table 1. 


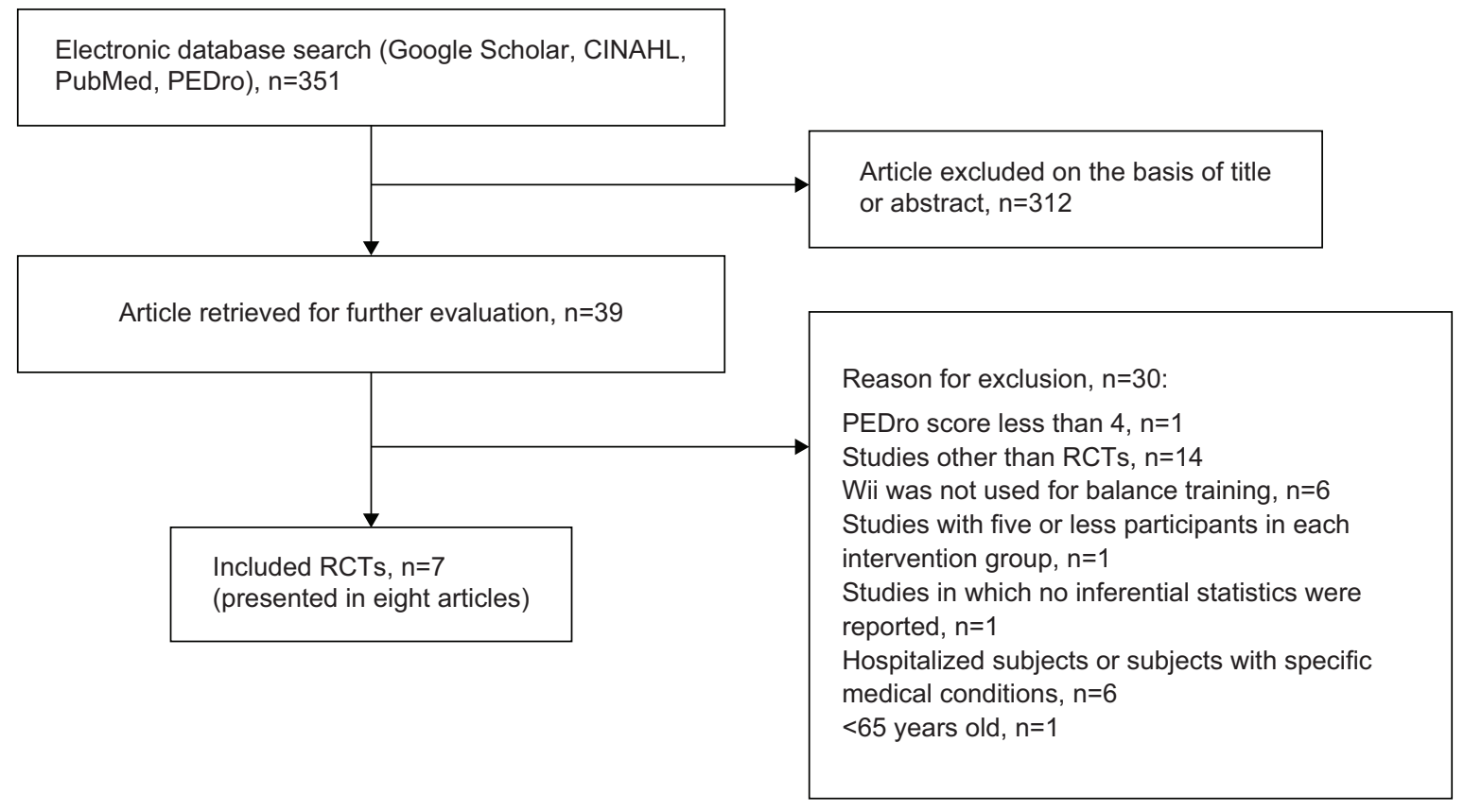

Figure I Results of the literature search conducted in June 2014. Abbreviation: RCT, randomized controlled trial.

\section{Methodological quality}

The methodological quality of the included papers according to the PEDro classification scale is presented in Table 2. The mean PEDro score was 5.57 (SD 0.78), with one study graded excellent (score 7/10), ${ }^{40}$ two good (score 6/10), ${ }^{38-41}$ and the rest fair (score 5/10). ${ }^{42-45}$

Four items were scored positive in all studies: "eligibility criteria", "random allocation", "baseline comparability", "point estimates and variability", and "adequate follow-up", while "between group comparison" was scored positive in most of the studies. In contrast, blindness of the participants or the therapists was impossible due to the nature of the studies, and only three studies maintained blindness of the assessor. ${ }^{38-41}$ Finally, "concealed allocation" 43,45 and "intention to treat" were rated positive in only two studies..$^{40,41}$

\section{Characteristics of included studies}

\section{Subjects}

The seven studies reviewed included 285 older adults, with 126 participating in VR-based training (Wii Fit) and 159 in control groups. The number of subjects per group ranged from nine to 30 subjects, with a mean of 14.5 (SD 7.13) and 14.18 (SD 6.03) subjects in the VR and control groups, respectively. Mean group ages ranged between 61.1 and 85.7 years, with a mean age of over 70.0 years reported in five studies. ${ }^{40-43,45}$

\section{VR intervention}

The majority of the studies utilized the Wii Balance Board for the VR interaction, and one also used the Wiimote console. ${ }^{42}$ With the exception of one study that included two groups training with the $\mathrm{Wii},{ }^{45}$ only one group participated in VR-based training in each study.

A variety of 27 games were used in the different studies. The number of different games per study varied from one ${ }^{44}$ to nine, ${ }^{43}$ with a mean of 5.85 (SD 2.85) games per study. "Soccer heading", "slalom ski", and "tight rope walk" were the most popular games and were used in four studies. The instructions regarding the interaction time with each game and the sequence of the games within the intervention period were extremely variable, as was the degree of detail provided to the reader regarding these parameters.

All the VR interventions were carried out in a clinical setting, and with the exception of one study, ${ }^{43}$ the participants were supervised during the interaction by an attending clinician. In two studies, additional precautions were taken, either by placing a chair in front of the participant ${ }^{45}$ or by using a gait belt, to allow for external support as necessary. ${ }^{41}$ In all studies, except for one in which subjects practiced in pairs, ${ }^{42}$ the games were played on a one-to-one basis.

\section{Control interventions}

Only in one study the control group received a placebo treatment as the subjects were informed that special copolymer 
shoe insoles may aid their balance..$^{40}$ In two studies with one control group, no treatment was offered; ${ }^{41,42}$ in one study that had two control groups, one received no treatment and the second received an alternative exercise program. ${ }^{45}$ In three additional studies, the control groups received an alternative exercise program. ${ }^{38,39,43,44}$ The alternative exercises for the control group varied between studies.

\section{Duration and number of treatments}

The duration of the VR intervention ranged from 6 to 20 weeks, with a mean of 10.57 (SD 4.85) weeks. The total number of treatments ranged from 12 to 24 , with a mean of 19.14 (SD 4.29). The length of treatment ranged from 35 to 90 minutes, with a mean of 57.85 (SD 17.76) minutes. Total treatment time ranged from 480 to 2,160 minutes, with a mean of 1,145.7 (SD 547.5) minutes.

\section{Outcome measures}

Assessments were carried out pre-intervention and immediately post-intervention in all the studies. An additional mid-term assessment was conducted in only one study. ${ }^{44}$ No study included follow-up assessments.

All of the studies employed at least one outcome measure that examined change in functional balance performance. The most frequently used measure was the Timed Up and Go (TUG) test, which was tested in all but one study that used unipedal stance time (eyes open and closed) and the Tinetti Balance test instead. ${ }^{45}$ While two studies did not include any additional functional tests, ${ }^{41,42}$ most studies incorporated additional clinical tests, such as the chair stand test, which is considered both a functional test and a general assessment of lower extremity strength. ${ }^{40,42,44}$ Other clinical tests included were the functional reach test, ${ }^{43,44}$ the Tinetti Balance test, ${ }^{43,45}$ the one-leg stance test, ${ }^{43,45}$ obstacle course completion, ${ }^{44}$ and the ten-step test. ${ }^{38}$ In addition to clinical balance tests, four studies incorporated instrumented measures of postural sway. $38,40,43,45$

Since no follow-up tests were included, none of the studies demonstrated a treatment effect on fall frequency. However, two studies included questionnaires examining treatment effect on fall risk, ${ }^{38,43}$ and four used a questionnaire ${ }^{38,40,41,43}$ to evaluate the intervention effect on fear of falling, which has been shown to be related to activity limitations and fall risk. $^{46,47}$

Other performance measures examined were fitness and muscle strength. The six-minute walk test was used to examine treatment effect on activity endurance in two studies ${ }^{42,44}$ and one study incorporated a senior fitness test. ${ }^{44}$ Effect on muscle strength was evaluated in three studies. ${ }^{40,42,44}$ Finally, measures of cognitive performance ${ }^{42}$ and depression were tested in only one study. ${ }^{41}$

\section{Treatment effect}

Due to methodological variability and insufficient data, the effects of Wii-based training could not be pooled for a meta-analysis. Thus, for example, while TUG was the most frequently used test, incorporated in all but one study, ${ }^{45}$ the distance walked in each direction was 3 meters in three studies ${ }^{39,40,43}$ and 8 feet in three studies. ${ }^{41,42,44}$ These differences, as well as insufficient data in two of the studies, ${ }^{41,42}$ along with different control interventions made it impossible to perform a meta-analysis.

All four studies comparing the VR group with no treatment or with a sham treatment indicated that VR training had a significant positive effect on the TUG test. ${ }^{40-42,45}$ Among the three studies that compared the Wii-based program with a different exercise program, Pluchino et $\mathrm{al}^{43}$ reported no significant improvement in TUG for either treatment group, similar improvements in both groups were noted by ReedJones et $\mathrm{al}^{44}$ and greater improvements in TUG were reported for the group receiving an alternative exercise program in the third study. ${ }^{39}$

Significantly greater effects were noted for the VR group when compared with a control group in the chair stand test, ${ }^{40,42}$ the six-minute walk test, ${ }^{42}$ and the Tinetti static test. ${ }^{45}$ Somewhat less consistent results were obtained when comparing the VR intervention with an alternative intervention. While Pluchino et $\mathrm{a}^{43}$ reported no significant effect on performance measures in either treatment group for the forward reach test and the Tinetti static test, ${ }^{43}$ Reed-Jones et $\mathrm{al}^{44}$ reported comparable improvements in both the VRbased and non-VR-based interventions for the chair stand test, the six-minute walk test, the forward reach test, the obstacle course test, and the Tinetti static test, and Singh et al reported comparable results for the ten-step test. ${ }^{38}$ A positive effect on postural sway measures were noted in three ${ }^{39,43,45}$ of four studies. ${ }^{40}$ Finally, the results of the balance self-efficacy questionnaires indicated improved self-confidence following Wii-based training in two studies, ${ }^{40,41}$ no significant improvement in one, ${ }^{43}$ and comparable positive results when the effect of Wii-based training was compared with an alternative exercise program. ${ }^{38}$

\section{Discussion}

The present systematic review was conducted to evaluate the effects of VR-based training with the Wii gaming console on 
Table I Study characteristics

\begin{tabular}{|c|c|c|c|}
\hline Study & $\begin{array}{l}\text { Subjects }(\mathbf{n}) \\
\text { (Males/females) } \\
\text { Age, years } \\
\text { Mean } \pm \text { SD }\end{array}$ & Intervention & CG intervention \\
\hline Jorgensen et $\mathrm{al}^{40}$ & $\begin{array}{l}\text { VR: } 28(9 / 19) \\
75.9 \pm 5.7 \\
\text { CG: } 30(9 / 21) \\
73.7 \pm 6.1\end{array}$ & $\begin{array}{l}\text { Wii Balance Board } \\
\text { Balance games: table tilt; slalom ski; perfect I0; right } \\
\text { rope walk; penguin slide; } \\
\text { Strength exercise: rowing squat. }\end{array}$ & $\begin{array}{l}\text { CG: placebo, copolymer shoe insoles, used } \\
\text { throughout, told may assist with balance }\end{array}$ \\
\hline Maillot et $\mathrm{al}^{42}$ & $\begin{array}{l}\text { VR: } 16 \\
73.47 \pm 4.1 \\
\text { CG: } 16 \\
73.47 \pm 3.0\end{array}$ & $\begin{array}{l}\text { WiiMote and Balance Board } \\
\text { Treatment period divided into three. Specific game } \\
\text { sequences per period. Games were played in pairs: } \\
\text { tennis; boxing; soccer headers; marbles; ski jump; ski } \\
\text { slalom; hula hoop; trampoline; return to serve tennis. }\end{array}$ & CG: no treatment \\
\hline Pluchino et $\mathrm{al}^{43}$ & $\begin{array}{l}\text { VR: I2 (4/8) } \\
70.72 \pm 8.46 \\
\text { CGI: I4 (6/8) } \\
78.4 \pm 4.5 \\
\text { CG2: I4 (5/9) } \\
76.0 \pm 7.74\end{array}$ & $\begin{array}{l}\text { Wii Balance Board } \\
\text { VR: } 5 / 8 \text { balance games daily for } 10 \text { minutes each (game } \\
\text { choice detailed). } \\
\text { Games: soccer heading; ski slalom; ski jumping; table } \\
\text { tilt; penguin slide; snowbird slalom; tightrope walker; } \\
\text { river bubble. }\end{array}$ & $\begin{array}{l}\text { CG1: Tai Chi Sun-style group program } \\
\text { CG2: group balance exercise program }\end{array}$ \\
\hline Reed-Jones et al ${ }^{44}$ & $\begin{array}{l}49(14 / 35) \\
\text { Age: } 67.5 \pm 5.9\end{array}$ & $\begin{array}{l}\text { Wii Balance Board } \\
\text { VR group: replace } 15 \text { minutes of cardiovascular exercise } \\
\text { with I5 VR, include } 15 \text { agility exercises as in CG } 2 \text {. } \\
\text { Game: dodging objects standing. }\end{array}$ & $\begin{array}{l}\text { All groups: program with cardiovascular, } \\
\text { strength, balance, and flexibility exercise } \\
\text { CGI: total } 35 \text { minutes of cardiovascular } \\
\text { exercise } \\
\text { CG2: I } 15 \text { minutes of agility exercise instead } \\
\text { of cardiovascular }\end{array}$ \\
\hline Rendon et $\mathrm{a}^{41}$ & $\begin{array}{l}\text { VR: } 16 \\
85.7 \pm 4.3 \\
\text { CG: } 18 \\
83.3 \pm 6.2 \\
35 \% \text { male }\end{array}$ & $\begin{array}{l}\text { Wii Balance Board } \\
\text { Games: lunges; single leg extension; twists. }\end{array}$ & No treatment \\
\hline Singh et $\mathrm{al}^{38,39}$ & $\begin{array}{l}\text { VR: } 18 \\
6 I . I \pm 3.7 \\
\text { CG: } 18 \\
64.0 \pm 5.9\end{array}$ & $\begin{array}{l}\text { Wii Balance Board } \\
\text { Games: ski slalom; table tilt; penguin slide; soccer } \\
\text { heading; tight rope walk; perfect I0; tilt city } \\
\text { Progression at self-determined pace. }\end{array}$ & $\begin{array}{l}\text { Five balance tasks: single leg stance; free leg } \\
\text { swing; moving objects and walking forward, } \\
\text { backward and sideways }\end{array}$ \\
\hline Toulotte et $\mathrm{a}^{45}$ & $\begin{array}{l}\text { VRI: } 9(4 / 5) \\
\text { Males } 70.2 \pm 8.8 \\
\text { Females } 73.8 \pm 9.2 \\
\text { VR2: } 9(3 / 6) \\
\text { Males } 75.7 \pm 5.5 \\
\text { Females } 76.8 \pm 4.7 \\
\text { CGI: } 9(3 / 6) \\
\text { Males } 84.3 \pm 5.1 \\
\text { Females } 84.2 \pm 9.7 \\
\text { CG2: } 9(4 / 5) \\
\text { Males } 69.6 \pm 9.10 \\
\text { Females } 71.8 \pm 8.0\end{array}$ & $\begin{array}{l}\text { Wii Balance Board } \\
\text { Games: soccer heading; ski jumping; downhill skiing; } \\
\text { yoga; game balls; tight rope walk. }\end{array}$ & $\begin{array}{l}\text { CGI: exercise program } \\
\text { CG2: no treatment }\end{array}$ \\
\hline
\end{tabular}

Note: *Author's confirmation regarding no supervision of Wii interaction, with no adverse effects.

Abbreviations: VR, virtual reality (experimental group); CG, control group; TUG, Timed Up and Go; NS, not significant; ABC, Activities-specific Balance Confidence Scale; LE, lower extremities; UE, upper extremities; COP, center of pressure; FES, Falls Efficacy Scale; 6MWT, six-minute walk test; RFD, rate of force development; SD, standard deviation; PPA, Physiological Profile Approach; Wiimote, Wii Remote. 


\begin{tabular}{|c|c|c|c|c|}
\hline Study & $\begin{array}{l}\text { I. Dwelling } \\
\text { 2. Exercise location } \\
\text { 3. Supervision }\end{array}$ & $\begin{array}{l}\text { Treatment/week } \times \text { weeks; } \\
\text { duration }\end{array}$ & Outcome measures & $\begin{array}{l}\text { Statistically } \\
\text { significant changes }\end{array}$ \\
\hline Jorgensen et $\mathrm{al}^{40}$ & $\begin{array}{l}\text { I. Community } \\
\text { 2. Clinic } \\
\text { 3. Yes }\end{array}$ & $\begin{array}{l}\text { VR: } \\
2 \times 10 \text { weeks; } \\
35 \pm 5 \text { minutes } \\
+25 \text { minutes LE strength } \\
\text { exercise }\end{array}$ & $\begin{array}{l}\text { Leg strength } \\
\text { RFD } \\
\text { COP velocity moment } \\
\text { TUG ( } 3 \text { meters) } \\
\text { FES (short form) } \\
\text { Chair Stand Test }\end{array}$ & $\begin{array}{l}\uparrow V R>C G \\
\uparrow V R>C G \\
\text { No group difference } \\
\downarrow V R>C G \\
\downarrow V R>C G \\
\uparrow V R>C G\end{array}$ \\
\hline Maillot et $\mathrm{al}^{42}$ & $\begin{array}{l}\text { I. Community } \\
\text { 2. Clinic } \\
\text { 3. Yes }\end{array}$ & $\begin{array}{l}\text { VR: } \\
2 \times 12 \text { weeks; } \\
60 \text { minutes }\end{array}$ & $\begin{array}{l}\text { Senior fitness test } \\
\text { TUG ( } 8 \text { feet) } \\
\text { LE and UE strength } \\
\text { UE flexibility } \\
\text { Heart rate in 6MWT } \\
\text { Cognitive tasks } \\
\text { Executive function } \\
\text { Visuospatial speed }\end{array}$ & $\begin{array}{l}\text { CG no change } \\
\downarrow V R>C G \\
\uparrow V R>C G \\
\uparrow V R>C G \text { in three of } \\
\text { four measures } \\
\uparrow V R>C G \\
\uparrow V R>C G \\
N S \\
\uparrow V R>C G\end{array}$ \\
\hline Pluchino et $\mathrm{al}^{43}$ & $\begin{array}{l}\text { I. Community } \\
\text { 2. All: clinic } \\
\text { 3. VR: no* }\end{array}$ & $\begin{array}{l}\text { All groups: } \\
2 \times 8 \text { weeks; } \\
60 \text { minutes ( } 5 \text { minutes warm-up, } \\
5 \text { minutes cool-down, } 50 \\
\text { exercises) }\end{array}$ & $\begin{array}{l}\text { FES } \\
\text { TUG ( } 3 \text { meters) } \\
\text { One leg stance } \\
\text { Functional reach } \\
\text { Tinetti test } \\
\text { Static and dynamic postural sway }\end{array}$ & $\begin{array}{l}\text { NS time, NS interaction } \\
\text { NS time, NS interaction } \\
\text { NS time, NS interaction } \\
\text { NS time, NS interaction } \\
\text { NS time, NS interaction } \\
\text { Comparable } \\
\text { improvements in all groups }\end{array}$ \\
\hline $\begin{array}{l}\text { Reed-Jones } \\
\text { et al }{ }^{44}\end{array}$ & $\begin{array}{l}\text { I. Community } \\
\text { 2. All: clinic } \\
\text { 3. Yes }\end{array}$ & $\begin{array}{l}\text { All groups: } \\
2 \times 12 \text { weeks } \\
90 \text { minutes }\end{array}$ & $\begin{array}{l}\text { UE strength } \\
6 M W T \\
\text { Forward reach } \\
\text { TUG ( } 8 \text { feet) } \\
\text { Fitness tests } \\
\text { Obstacle course completion time } \\
\text { Obstacle course collisions }\end{array}$ & $\begin{array}{l}\uparrow \text { All groups } \\
V R=C G \\
V R=C G \\
V R=C G \\
V R=C G \\
V R=C G \\
V R>C G\end{array}$ \\
\hline Rendon et $\mathrm{al}^{41}$ & $\begin{array}{l}\text { I. Retirement } \\
\text { community } \\
\text { 2. Clinic } \\
\text { 3. Yes + gait belt }+ \\
\text { external support as } \\
\text { needed }\end{array}$ & $\begin{array}{l}\text { VR: } \\
3 \times 6 \text { weeks; } \\
60 \text { minutes } \\
\text { ( } 8 \text { minutes cycling warm-up and } \\
8 \text { minutes cool-down, 35-45 } \\
\text { exercises) } \\
\text { CG: none }\end{array}$ & $\begin{array}{l}\text { ABC } \\
\text { Geriatric Depression Scale } \\
\text { TUG (8 feet) }\end{array}$ & $\begin{array}{l}\uparrow \mathrm{VR}>\mathrm{CG} \\
\mathrm{NS} \\
\downarrow \mathrm{VR}>\mathrm{CG}\end{array}$ \\
\hline Singh et $\mathrm{al}^{38,39}$ & $\begin{array}{l}\text { 1. Community } \\
\text { 2. VR and CG: clinic } \\
\text { 3. Yes }\end{array}$ & $\begin{array}{l}\text { VR and CG: } \\
2 \times 6 \text { weeks } \\
40 \text { minutes ( } 10 \text { minutes warm-up } \\
\text { and cool-down; } 30 \text { minutes of } \\
\text { exercise) }\end{array}$ & $\begin{array}{l}\text { Fall risk (PPA) } \\
\text { ABC-6 (short version) } \\
\text { Postural sway } \\
\text { TUG ( } 3 \text { meters) } \\
\text { Ten-step test }\end{array}$ & $\begin{array}{l}\uparrow \text { Both } \\
\uparrow \text { Both } \\
\downarrow \text { Both groups } \\
\downarrow \text { Both, VR }<\text { CG } \\
\uparrow \text { Both groups }\end{array}$ \\
\hline Toulotte et $\mathrm{al}^{45}$ & $\begin{array}{l}\text { I. Retirement center } \\
\text { 2. All except CG2: } \\
\text { clinic } \\
\text { 3. Yes + chair in front }\end{array}$ & $\begin{array}{l}\text { All treatment groups } \\
\text { I } \times 20 \text { weeks; } 60 \text { minutes } \\
\text { VRI: only VR } \\
\text { VR2: } 30 \text { minutes exercise and } \\
30 \text { minutes VR }\end{array}$ & $\begin{array}{l}\text { Unipedal stance } \\
\text { Tinetti (static) } \\
\text { Tinetti (dynamic) } \\
\text { COP position }\end{array}$ & $\begin{array}{l}\text { VR2; } \uparrow \mathrm{CGI} \\
\downarrow \mathrm{VRI} ; \downarrow \mathrm{VR} 2 ; \\
\downarrow \mathrm{CGI} \\
\downarrow \mathrm{VR} 2 ; \downarrow \mathrm{CGI} \\
\uparrow \mathrm{VR} 2\end{array}$ \\
\hline
\end{tabular}




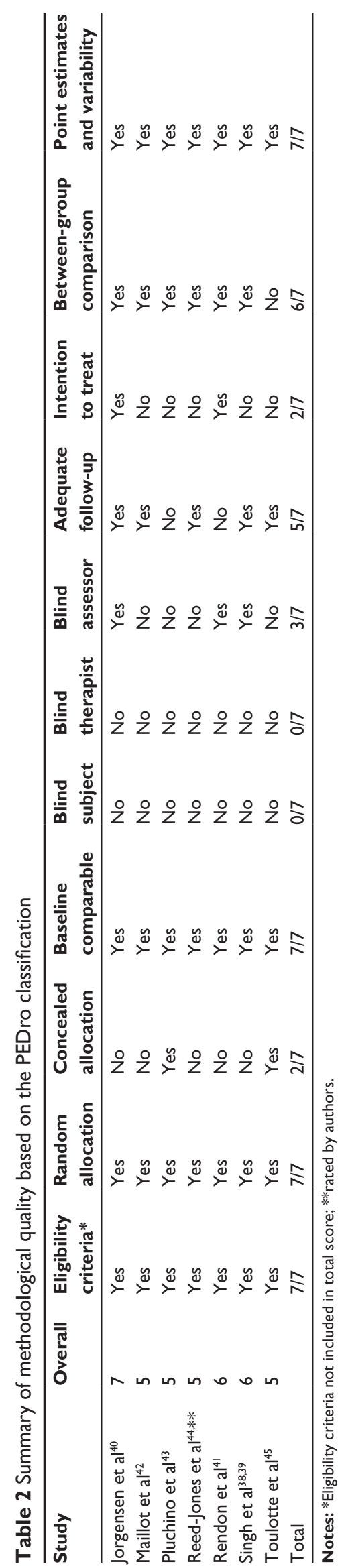

balance control and functional performance in independently functioning older adults. The literature review revealed a rapidly growing interest in the potential of this system as an exercise modality for this population. Whereas only sporadic reports that were not well controlled appeared in the literature in the first few years immediately following the introduction of Wii (2006-2011), seven randomized controlled studies examining the effects of Wii-based interventions on balance control among older adults living in the community were published in the years 2012-2014. However, the tremendous methodological variability among studies, as well as some methodological limitations, made it impossible to conduct a comprehensive meta-analysis.

The four studies examining the effects of Wii-based exercise programs in comparison with no exercise indicate that Wii-based training may serve as a means to improve balance control and self-confidence among community-dwelling older adults..$^{40-42,45}$ The studies comparing Wii-based training with alternative exercise programs further support this conclusion, as the balance improvements achieved with Wii-based training were comparable with those achieved with other exercise programs in several of the tested outcome measures. Nevertheless, this conclusion must be regarded with caution. While both groups demonstrated improvements in TUG in the study by Singh et a ${ }^{39}$ greater gains were noted in the group that completed a conventional exercise program. In contrast, Pluchino et $\mathrm{al}^{43}$ showed comparable improvements only in measures of postural sway, with no change in functional balance performance in either treatment group. Finally, while Reed-Jones et al ${ }^{44}$ reported comparable improvements in balance performance measures in all treatment groups, it should be noted that the group receiving Wii-based training also participated in additional balance and strength exercises that may have led to the observed improvements. However, this study demonstrated that substituting 15 minutes of cardiovascular training with Wii-based training enhanced the subjects' obstacle avoidance behavior. This may be related to improved visual processing and attention, which are targeted during Wii-based training. Thus, the advantage of VR-based training may contribute to processes not captured by the more standard performance measures examined in most studies. As the fall incidence in older adults has been shown to be related to their ability to maintain balance while performing cognitively demanding tasks (ie, dual tasking), ${ }^{48-51}$ future studies should further investigate the effects of VR-based training on these abilities and their relationship to fall prevention.

To be suitable as a home-based treatment modality, it is necessary to determine that older adults can use the Wii 
system safely without supervision. Only one of the reviewed articles noted that the subjects performed the Wii-based intervention at their own convenience, albeit at the clinic, but apparently without supervision. ${ }^{43}$ Further, only one article addressed the issue of adverse effects, stating that none were reported. ${ }^{40}$ Thus, based on this systematic review, it is not possible to make a statement regarding the suitability of this intervention for independent use by older adults. To the best of our knowledge, only two non-randomized studies examined home usage of the Wii system for balance enhancement in older adults. Agmon et al in a pilot study of seven subjects with impaired balance, modified two of the four Wii games used in order to ensure the participants' safety. Additionally, more than five 30-minute training sessions were necessary beyond the first week of use to ensure that the participants were confident with the activities. ${ }^{34}$ In a more recent study, a group of 21 elderly subjects with no balance impairments undertook unsupervised Wii-based balance training performed in pairs. During a six-week treatment period (30-minute interactions three times per week), two subjects ceased participation due to exacerbation of low back pain, which did not require medical treatment. No acute adverse events were reported during the VR interaction. ${ }^{52}$ The ability to use the Wii system independently in the home environment must be considered in future studies, taking into account the subjects' ages as well as factors such as initial balance performance, comorbidities and cognitive states.

A variety of games were used in the different studies, of which the three most popular were the "soccer heading", "slalom ski", and "tight rope walk". These games were probably chosen since they require adequate core muscle control and upper and lower limb muscle strength for rapid and accurate movements. The games challenged the subjects' balance by requiring them to lean in different directions and to take sharp turns, thus shifting their center of mass to the limits of their base of support. The chosen games also appeared to encourage moderate to vigorous physical exertion. It is interesting to note, that in the pilot study noted above, Agmon et $\mathrm{al}^{34}$ reported safety concerns and muscle strains with the "basic step" and "soccer heading" games, respectively. ${ }^{34}$ Yet, "soccer heading" was employed in four of the seven studies included in the present review. ${ }^{38,39,42,43,45}$ Future studies are necessary to optimize the use of Wii-based balance training in terms of game choice and treatment intensity.

It has been repeatedly suggested that engaging in fun and challenging VR games may strongly affect an individual's motivation to apply maximal effort and thus increase overall compliance with treatment. ${ }^{53}$ Although level of motivation and enjoyment were not documented in the reviewed articles, Wii-based interventions have been reported as enjoyable for balance training in nonimpaired elderly adults, ${ }^{52,54}$ as well as in individuals following traumatic brain injury. ${ }^{55}$ Further, one of the reviewed articles reported a very high level of adherence to the program and an interest in continued use of this modality at home. ${ }^{42}$ In addition to their effect on compliance, Wii-based games are well suited for home-based exercise programs, as they are relatively inexpensive, and do not require large spaces or additional peripheral equipment. These important attributes render this modality particularly appealing for older adults, who are expected to engage in exercise programs to counter the negative consequences of aging and a sedentary lifestyle, but may find it difficult to participate in formal exercise activities that entail time, place, and cost constraints.

In conclusion, the present review of seven randomized controlled trials indicates that engaging older adults living in the community in a Wii-based exercise program is feasible and may enhance their balance capabilities. Thus, such programs may serve as an alternative to more conventional forms of exercise aimed at improving balance control. However, studies vary greatly in terms of their methodological quality and the intervention protocols and outcome measures used. Better designed, randomized controlled studies, including larger group sizes, follow-up assessments, as well as more standardized protocols and outcome measures are necessary before definitive statements can be made regarding the potential of a Wii-based intervention as a safe and effective homebased treatment for community living, elderly individuals. Future studies should provide more detailed guidelines as to the optimal treatment and implementation protocols.

\section{Disclosure}

The authors report no conflicts of interest in this work.

\section{References}

1. Lord SR, Ward JA, Williams P, Anstey KJ. An epidemiological study of falls in older community-dwelling women: the Randwick falls and fractures study. Aust J Public Health. 1993;17(3):240-245.

2. Ganz DA, Bao Y, Shekelle PG, Rubenstein LZ. Will my patient fall? JAMA. 2007;297(1):77-86.

3. Bialoszewski D, Slupik A, Lewczuk E, Gotlib J, Mosiolek A, Mierzwinska A. Incidence of falls and their effect on mobility of individuals over 65 years of age relative to their place of residence. Ortop Traumatol Rehabil. 2008;10(5):441-448.

4. Zijlstra GA, van Haastregt JC, van Eijk JT, van Rossum E, Stalenhoef PA, Kempen GI. Prevalence and correlates of fear of falling, and associated avoidance of activity in the general population of community-living older people. Age Ageing. 2007;36(3):304-309.

5. World Health Organization. Global report on falls in older age. 2007. Available from: http://www.who.int/ageing/publications/ Falls_prevention7March.pdf. Accessed July 8, 2013. 
6. Kelly KD, Pickett W, Yiannakoulias N, et al. Medication use and falls in community-dwelling older persons. Age Ageing. 2003;32(5): 503-509.

7. Lord SR. Visual risk factors for falls in older people. Age Ageing. 2006;35 Suppl 2:ii42-ii45.

8. Muir SW, Gopaul K, Montero Odasso MM. The role of cognitive impairment in fall risk among older adults: a systematic review and meta-analysis. Age Ageing. 2012;41(3):299-308.

9. Carter ND, Kannus P, Khan KM. Exercise in the prevention of falls in older people: a systematic literature review examining the rationale and the evidence. Sports Med. 2001;31(6):427-438.

10. Lord SR, Ward JA, Williams P, Strudwick M. The effect of a 12-month exercise trial on balance, strength, and falls in older women: a randomized controlled trial. J Am Geriatr Soc. 1995;43(11): 1198-1206.

11. Steadman J, Donaldson N, Kalra L. A randomized controlled trial of an enhanced balance training program to improve mobility and reduce falls in elderly patients. $J$ Am Geriatr Soc. 2003;51(6):847-852.

12. Sherrington C, Whitney JC, Lord SR, Herbert RD, Cumming RG, Close JC. Effective exercise for the prevention of falls: a systematic review and meta-analysis. J Am Geriatr Soc. 2008;56(12):2234-2243.

13. Low S, Ang LW, Goh KS, Chew SK. A systematic review of the effectiveness of Tai Chi on fall reduction among the elderly. Arch Gerontol Geriatr. 2009;48(3):325-331.

14. Wolf SL, Barnhart HX, Kutner NG, McNeely E, Coogler C, Xu T. Selected as the best paper in the 1990s: Reducing frailty and falls in older persons: an investigation of tai chi and computerized balance training. J Am Geriatr Soc. 2003;51(12):1794-1803.

15. Holden MK. Virtual environments for motor rehabilitation: review. Cyberpsychol Behav. 2005;8(3):187-207.

16. Rizzo AA. Virtual reality and disability: emergence and challenge. Disabil Rehabil. 2002;4:567-569.

17. Rizzo AA, Kim GJ. A SWOT analysis of the field of virtual reality rehabilitation and therapy. Presence Teleoper Virtual Environ. 2005;14(2):1190146.

18. Sveistrup H. Motor rehabilitation using virtual reality. $J$ Neuroeng Rehabil. 2004;1(10):1-8.

19. Glegg SM, Tatla SK, Holsti L. The GestureTek virtual reality system in rehabilitation: a scoping review. Disabil Rehabil Assist Technol. 2014;9(2):89-111.

20. Ma HI, Hwang WJ, Fang JJ, et al. Effects of virtual reality training on functional reaching movements in people with Parkinson's disease: a randomized controlled pilot trial. Clin Rehabil. 2011;25(10):892-902.

21. Bryanton C, Bosse J, Brien M, McLean J, McCormick A, Sveistrup H. Feasibility, motivation, and selective motor control: virtual reality compared to conventional home exercise in children with cerebral palsy. Cyberpsychol Behav. 2006;9(2):123-128.

22. Owens SG, Garner JC III, Loftin JM, van Blerk N, Ermin K. Changes in physical activity and fitness after 3 months of home Wii Fit ${ }^{\mathrm{TM}}$ use. J Strength Cond Res. 2011;25(11):3191-3197.

23. Warburton DE, Bredin SS, Horita LT, et al. The health benefits of interactive video game exercise. Appl Physiol Nutr Metab. 2007;32(4):655-663.

24. Jelsma J, Pronk M, Ferguson G, Jelsma-Smit D. The effect of the Nintendo Wii Fit on balance control and gross motor function of children with spastic hemiplegic cerebral palsy. Dev Neurorehabil. 2013; 16(1):27-37.

25. Lotan M, Yalon-Chamovitz S, Weiss PL. Improving physical fitness of individuals with intellectual and developmental disability through a virtual reality intervention program. Res Dev Disabil. 2009;30(2):229-239.

26. Mouawad MR, Doust CG, Max MD, McNulty PA. Wii-based movement therapy to promote improved upper extremity function post-stroke: a pilot study. J Rehabil Med. 2011;43(6):527-533.

27. Larsen LH, Schou L, Lund HH, Langberg H. The physical effect of exergames in healthy elderly a systematic review. Games for Health Journal. 2013;2(4):205-212.
28. Taylor MJ, McCormick D, Impson R, Shawis T, Griffin M. Activity promoting gaming systems in exercise and rehabilitation. J Rehabil Res Dev. 2011;48(10):1171-1186.

29. Pietrzak E, Cotea C, Pullman S. Using commercial video games for upper limb stroke rehabilitation: is this the way of the future? Top Stroke Rehabil. 2014;21(2):152-162.

30. Barry G, Galna B, Rochester L. The role of exergaming in Parkinson's disease rehabilitation: a systematic review of the evidence. J Neuroeng Rehabil. 2014;11(1):33

31. National Stroke Foundation. National Stroke Audit Rehabilitation Services: Data Supplement 2012. Available from: http://strokefoundation. com.au/site/media/2012-Supplementary-data.pdf. Accessed September 10, 2014.

32. Clark R, Kraemer T. Clinical use of Nintendo Wii bowling simulation to decrease fall risk in an elderly resident of a nursing home: a case report. J Geriatr Phys Ther. 2009;32(4):174-180.

33. Miller CA, Hayes DM, Dye K, Johnson C, Meyers J. Using the Nintendo Wii Fit and body weight support to improve aerobic capacity, balance, gait ability, and fear of falling: two case reports. J Geriatr Phys Ther. 2012;35(2):95-104.

34. Agmon M, Perry CK, Phelan E, Demiris G, Nguyen HQ. A pilot study of Wii Fit exergames to improve balance in older adults. J Geriatr Phys Ther. 2011;34(4):161-167.

35. Bateni H. Changes in balance in older adults based on use of physical therapy vs the Wii Fit gaming system: a preliminary study. Physiotherapy. 2012;98(3):211-216.

36. Liberati A, Altman DG, Tetzlaff J, et al. The PRISMA statement for reporting systematic reviews and meta-analyses of studies that evaluate health care interventions: explanation and elaboration. J Clin Epidemiol. 2009;62(10):e1-e34.

37. Sherrington C, Herbert RD, Maher CG, Moseley AM. PEDro: a database of randomized trials and systematic reviews in physiotherapy. Man Ther. 2000;5:223-226.

38. Singh DK, Rajaratnam BS, Palaniswamy V, Pearson H, Raman VP, Bong PS. Participating in a virtual reality balance exercise program can reduce risk and fear of falls. Maturitas. 2012;73(3):239-243.

39. Singh DK, Rajaratnam BS, Palaniswamy V, Raman VP, Bong PS, Pearson H. Effects of balance-focused interactive games compared to therapeutic balance classes for older women. Climacteric. 2013;16(1):141-146.

40. Jorgensen MG, Laessoe U, Hendriksen C, Nielsen OB, Aagaard P. Efficacy of Nintendo Wii training on mechanical leg muscle function and postural balance in community-dwelling older adults: a randomized controlled trial. J Gerontol A Biol Sci Med Sci. 2013;68(7):845-852.

41. Rendon AA, Lohman EB, Thorpe D, Johnson EG, Medina E, Bradley B. The effect of virtual reality gaming on dynamic balance in older adults. Age Ageing. 2012;41(4):549-552.

42. Maillot P, Perrot A, Hartley A. Effects of interactive physical-activity video-game training on physical and cognitive function in older adults. Psychol Aging. 2012;27(3):589-600.

43. Pluchino A, Lee SY, Asfour S, Roos BA, Signorile JF. Pilot study comparing changes in postural control after training using a video game balance board program and 2 standard activity-based balance intervention programs. Arch Phys Med Rehabil. 2012;93(7):1138-1146.

44. Reed-Jones RJ, Dorgo S, Hitchings MK, Bader JO. WiiFit Plus balance test scores for the assessment of balance and mobility in older adults. Gait Posture. 2012;36(3):430-433.

45. Toulotte C, Toursel C, Olivier N. Wii Fit(R) training vs adapted physical activities: which one is the most appropriate to improve the balance of independent senior subjects? A randomized controlled study. Clin Rehabil. 2012;26(9):827-835.

46. Hita-Contreras F, Martinez-Amat A, Lomas-Vega R, et al. Predictive value of stabilometry and fear of falling on falls in postmenopausal women. Climacteric. 2012;16(5):584-589

47. Yoo IY. Recurrent falls among community-dwelling older Koreans: prevalence and multivariate risk factors. J Gerontol Nurs. 2011;37(9): $28-40$. 
48. Beauchet O, Annweiler C, Dubost V, et al. Stops walking when talking: a predictor of falls in older adults? Eur J Neurol. 2009;16(7):786-795.

49. Condron JE, Hill KD. Reliability and validity of a dual-task force platform assessment of balance performance: effect of age, balance impairment, and cognitive task. J Am Geriatr Soc. 2002;50(1):157-162.

50. Hauer K, Marburger C, Oster P. Motor performance deteriorates with simultaneously performed cognitive tasks in geriatric patients. Arch Phys Med Rehabil. 2002;83(2):217-223.

51. Nordin E, Moe-Nilssen R, Ramnemark A, Lundin-Olsson L. Changes in step-width during dual-task walking predicts falls. Gait Posture. 2010;32(1):92-97.

52. Nicholson VP, McKean M, Lowe J, Fawcett C, Burkett B. Six weeks of unsupervised Nintendo Wii Fit gaming is effective at improving balance in independent older adults. J Aging Phys Act. February 28, 2014. [Epub ahead of print].
53. Jack D, Boian R, Merians AS, et al. Virtual reality-enhanced stroke rehabilitation. IEEE Trans Neural Syst Rehabil Eng. 2001;9(3):308-318.

54. Meldrum D, Glennon A, Herdman S, Murray D, McConn-Walsh R. Virtual reality rehabilitation of balance: assessment of the usability of the Nintendo Wii ${ }^{\circledR}$ Fit Plus. Disabil Rehabil Assist Technol. 2012;7(3):205-210.

55. Cuthbert JP, Staniszewski K, Hays K, Gerber D, Natale A, O’Dell D. Virtual reality-based therapy for the treatment of balance deficits in patients receiving inpatient rehabilitation for traumatic brain injury Brain Inj. 2014;28(2):181-188.

\section{Clinical Interventions in Aging}

\section{Publish your work in this journal}

Clinical Interventions in Aging is an international, peer-reviewed journal focusing on evidence-based reports on the value or lack thereof of treatments intended to prevent or delay the onset of maladaptive correlates of aging in human beings. This journal is indexed on PubMed Central, MedLine,

\section{Dovepress}

CAS, Scopus and the Elsevier Bibliographic databases. The manuscript management system is completely online and includes a very quick and fair peer-review system, which is all easy to use. Visit http://www.dovepress. com/testimonials.php to read real quotes from published authors. 